\title{
Protocolos emergentes na comunicação organizacional no atual patamar de mediação estrutural da tecnicidade
}

\section{Mônica Bertholdo Pieniz}

Doutora; Universidade Federal do Rio Grande do Sul; Porto Alegre, RS, Brasil monica.pieniz@ufrgs.br

\begin{abstract}
Resumo
Este artigo é resultado de uma trajetória de pesquisa que tem como eixo teórico principal o conceito de tecnicidade, de Jesús Martín-Barbero, e traz os resultados de uma pesquisa qualitativa que teve por objetivo compreender o processo de reconfiguração da comunicação organizacional no atual patamar de mediação da tecnicidade, na relação com os diferentes públicos nas redes sociais da web. Tal pesquisa buscou responder a questão: como tem se dado a gestão das diferentes possibilidades de comunicação organizacional a partir das tecnologias de informação e comunicação? Para isso, gestores da comunicação de organizações, que representam o primeiro, o segundo e o terceiro setor, foram entrevistados. Os resultados apontam a constituição de diferentes tipos de protocolos na gestão da comunicação nas organizações, como os de emissão, interação, recepção/monitoramento, regulação, gestão de crise, registro e análise e inovação por demanda.
\end{abstract}

\section{Palavras-chave}

Mediação estrutural da tecnicidade. Convergência midiática. Comunicação organizacional. Gestão da comunicação. Recepção.

\section{Introdução}

O conceito de mediação da tecnicidade, de Jesús Martín-Barbero, tem tomado espaço nas discussões da área da comunicação, e, para a autora desse artigo, começou a ser o eixo teórico central desde sua tese de doutorado, no âmbito das audiências de telenovela no Twitter (PIENIZ, 2013; 2015a; 2015b). Após a conclusão do doutorado, 
novos desafios profissionais a levaram à demanda de investigar a perspectiva das organizações sobre este cenário de reconfiguração comunicacional (PIENIZ, 2015b). A partir disso, um novo projeto delineou-se, o qual tem parte dos seus resultados aqui compartilhados.

Os achados expostos a seguir, portanto, decorrem de uma pesquisa qualitativa que teve como tema as reconfigurações da comunicação organizacional, a partir da apropriação tecnológica nas relações entre organizações e públicos nas redes sociais da web; e propõe uma aproximação entre as áreas de recepção, estudos culturais, relações públicas e comunicação organizacional ${ }^{1}$, a partir da perspectiva da mediação da tecnicidade. Percebe-se um cenário no qual as tecnologias de informação e comunicação propiciaram uma diversidade de meios, para sistematizar o relacionamento das organizações com os seus públicos. Consequentemente, tal relação é objeto constante de mudanças, as quais demandam diferentes estratégias de pesquisa, planejamento, gestão e avaliação por parte das organizações.

O que aqui se denomina como mediação estrutural da tecnicidade (MARTÍNBARBERO, 2010), em sinergia com outras mediações, colabora para a análise do que reconfigura as possibilidades de atuação das organizações na contemporaneidade. Tal mediação é aqui considerada uma condição comunicacional contemporânea que revela um trânsito das audiências (OROZCO-GÓMEZ, 2011). Essas são compreendidas como receptores da comunicação organizacional, os quais, além de receberem as mensagens e interagirem pelos meios tradicionais, podem também, hoje, optar pela emissão de mensagens em espaços de maior alcance, tendo ou não o crivo dos profissionais das organizações que são pauta dos conteúdos.

Este trânsito afeta as organizações, também, na medida em que essas precisam tornar-se receptoras das emissões por parte do público e, a partir disso, sentem a necessidade de moldar a sua comunicação nesses novos espaços. E este é o foco desta pesquisa, não só o olhar da organização como receptora, mas também como produtora e interagente. Organizações e públicos intercalam papeis de emissão e recepção (PIENIZ, 2015b) e, portanto, figuram como audiências em trânsito em diferentes momentos e espaços, podendo ou não estar em interação mútua (PRIMO, 2008).

\footnotetext{
${ }^{1}$ Nesse sentido, destaca-se a contribuição dos grupos de pesquisa da Universidade Federal do Rio Grande do Sul (UFRGS), registrados no Conselho Nacional de Desenvolvimento e Pesquisa (CNPq) sob os nomes: "Comunicação e práticas culturais", coordenado por Nilda Aparecida Jacks e Elisa Reinhardt Piedras e "Comunicação Organizacional, Cultura e Relações de Poder", coordenado por Rudimar Baldissera. As discussões decorrentes de tais grupos foram propícias para o desenvolvimento do trabalho.
} 
Diante do contexto anteriormente exposto, a questão que emerge é: como tem se dado a gestão das diferentes possibilidades de comunicação organizacional a partir das tecnologias de informação e comunicação em organizações que representam o primeiro, o segundo e o terceiro setor? 0 objetivo é compreender o processo de reconfiguração da comunicação organizacional no atual patamar de mediação da tecnicidade (MARTÍNBARBERO, 2010) e na relação com os diferentes públicos nas redes sociais da web. Para a realização da pesquisa, três organizações foram selecionadas: uma universidade federal, uma concessionária de rodovias e uma organização hospitalar, representando, respectivamente, o primeiro, o segundo e o terceiro setor.

A ideia de trazer três diferentes organizações partiu do interesse de compreender como se processava a gestão da comunicação nas redes sociais da web em organizações com fluxo financeiro e propósitos diferenciados, como uma forma de contrapor as realidades. Isso não significa que esse trabalho esgote as possibilidades de comparação, mas há diferenças que precisam ser consideradas, no que tange às manifestações da mediação estrutural da tecnicidade (MARTÍN-BARBERO, 2010) em cada realidade estudada. Foram entrevistados quatro gestores da comunicação organizacional, sendo, portanto, ocupantes dos cargos de chefia na área de comunicação. Com exceção da organização hospitalar, na qual o gestor tem formação na área de marketing, os demais informantes têm formação na área de jornalismo².

\section{A tecnicidade no âmbito da comunicação organizacional}

Para fundamentar teoricamente este cenário empírico que concerne às reconfigurações na comunicação organizacional, decorrente do trânsito das audiências (OROZCO-GÓMEZ, 2011), a discussão parte, fundamentalmente, do conceito de mediação de Martín-Barbero (2008), especialmente, o de mediação da tecnicidade, o qual é aqui desdobrado na convergência tecnológica e midiática (JENKINS, 2008) e nos processos em via de midiatização. Este desdobramento é posto como uma hierarquização conceitual que

\footnotetext{
${ }^{2}$ A investigação destas organizações dependeu, além da autorização do Comitê de Ética da universidade (na qual o projeto foi registrado sob número 28067, e na Plataforma Brasil, com Certificado de Apresentação para Apreciação Ética (CAAE, registrado sob número 50850015.9.0000.5347), do aceite por parte de seus representantes — documentados, respectivamente, a partir de um termo de concordância para a empresa e de um termo de consentimento livre e esclarecido para os gestores. A pesquisa foi realizada nos anos de 2016 e 2017 e optou por preservar o anonimato dos envolvidos, não apresentando a identidade dos informantes nem das organizações investigadas, as quais foram escolhidas por julgamento do pesquisador, levando em conta critérios como: histórico do setor de comunicação das organizações, presença oficial nas redes sociais da web e facilidade de acesso ao contato com os gestores, ou seja, todas as organizações estão situadas em Porto Alegre.
} 
almeja explicar fenômenos extremamente complexos e imbricados, relacionados à mediação tecnológica.

Sendo uma espécie de estrutura incrustada nas práticas sociais cotidianas, as mediações são tomadas como parte da vida dos sujeitos (MARTíN-BARBERO, 2004), na qual a complexa trama envolvendo tecnologia, comunicação e cultura é tema de constante preocupação para os pesquisadores. A tecnicidade é a capacidade de inovação dos formatos industriais e das formas de receber mensagens midiáticas. Ela é "[...] menos assunto de aparatos do que de operadores perceptivos e destrezas discursivas." (MARTÍNBARBERO, 2008, p. 18). Parte-se do que explica Martín-Barbero (2010, p. 49, tradução nossa):

\begin{abstract}
É mesmo o lugar da cultura que muda na sociedade quando a mediação tecnológica da comunicação deixa de ser instrumental para tornar-se mais espessa, mais densa, e se converter em estrutural. Pois a tecnologia remete hoje não somente, e não tanto, à novidade dos aparatos, mas a novos modos de percepção e de linguagem, a novas sensibilidades e escrituras. [...] a tecnologia deslocaliza os saberes, modificando tanto o estatuto cognitivo como o institucional [...], o que está conduzindo a um forte borramento das fronteiras entre razão e imaginação, saber e informação, natureza e artificialidade, arte e ciência [... $]^{3}$.
\end{abstract}

Como demonstrado nas diferentes ideias de mapas propostos por Martín-Barbero (2008; 2009) e na análise empírica dos meios, a tecnicidade adquiriu diversas formas ao longo do desenvolvimento das condições comunicacionais de cada tempo. Contemporaneamente, é percebida, com mais impacto, pelo processo de midiatização alavancado pela convergência que permite esta situação de trânsito para as mutações culturais. Entende-se, aqui, a convergência tecnológica como o estado material da tecnicidade hoje (PIENIZ, 2013). A convergência midiática está engendrada no tecido social com formas que retomam o oral, perpassam o massivo e instituem uma nova forma de comunicar, no qual antes os agentes tinham as limitações da comunicação comunitária e, hoje, têm seu próprio espaço midiático.

\footnotetext{
${ }^{3}$ Original: "Es el lugar mismo de la cultura em la sociedade el que cambia cuando la mediación tecnológica de la comunicación deja de ser instrumental para espesarse, densificarse y convertirse em estructural. Pues la tecnología remite hoy no solo y no tanto a la novedad de los aparatos, sino a nuevos modos de percepción y de lenguaje, a nuevas sensibilidades y escrituras [...] la tecnología deslocaliza los saberes modificando tanto el estatuto cognitivo como institucional [...], lo que está conduciendo a um fuerte borronamiento de las fronteras entre razón e imaginación, saber e información, naturaliza y artificio, arte y ciência $[. . .]^{\prime \prime}$.
} 
A convergência das mídias é mais do que apenas uma mudança tecnológica. A convergência altera a relação entre tecnologias existentes, indústrias, mercados, gêneros e públicos [...] a convergência refere-se a um processo, não a um ponto final. Não haverá uma caixa preta que controlará o fluxo midiático para dentro de nossas casas. Graças à proliferação de canais e à portabilidade das novas tecnologias de informática e telecomunicações, estamos entrando numa era em que haverá mídias em todos os lugares. (JENKINS, 2008, p. 41).

Entretanto, ao falarmos de participação, a questão do acesso amplia-se para além das tecnologias. A participação implica a reflexão acerca dos protocolos e das práticas culturais (JENKINS, 2008). Os atuais participantes dessas apropriações influenciam relevantemente a cultura midiática. As contendas e as conciliações resultantes do uso das tecnologias irão definir a cultura pública do futuro, hoje, protagonizada prioritariamente por jovens. Eles compõem grande parte do novo grupo de consumidores que são ativos, migrantes, conectados socialmente, barulhentos e públicos.

Na medida em que a convergência midiática, propiciada pela convergência de tecnologias, deixa visível o caráter estrutural da tecnicidade, percebe-se a intensificação de alguns processos de midiatização da sociedade a partir da apropriação desta tecnologia pelos receptores, por exemplo. A convergência de fatores sócio-tecnológicos, de acordo com Fausto Neto (2008), difundidos segundo lógicas de ofertas e de usos sociais, produziu - sobretudo nas três últimas décadas - profundas e complexas alterações na constituição societária, nas suas formas de vida e interações. Ocorre a disseminação de novos protocolos técnicos na sociedade, os quais são apropriados pela parte que tem mais acesso à tecnologia, o que intensifica os processos que vão transformando tecnologias em meios de produção, circulação e recepção de discursos. Mesmo que ainda, na minoria da população, tal apropriação venha aumentando constantemente e, também, reconfigurando processualmente as práticas sociais.

Observa-se, de forma não totalizante, nem homogênea, uma mudança da "sociedade midiática" a "sociedade midiatizada" (KEGLER, 2008), caracterizada pelas mudanças da vida institucional, da vida pública, dos meios e dos processos que possibilitam as relações entre organizações, grupos e indivíduos. 0 universo físico das sociedades pode ser o mesmo, mas o universo simbólico do social está, em parte, na era da "sociedade midiática" e, em parte, na "sociedade midiatizada", constituindo esse momento de trânsito, no qual não se considera uma sociedade como evolução da outra, visto que são apenas modos diferentes que coabitam na realidade empírica. 
Este contexto se reflete na comunicação organizacional, uma vez que essa é uma disciplina interessada na forma de processamento do "[...] fenômeno comunicacional dentro das organizações no âmbito da sociedade global. Ela analisa o sistema, o funcionamento e o processo de comunicação entre as organizações e seus diversos públicos" (KUNSCH, 2003, p. 149). A excelência desta comunicação, conforme Grunig (2011), significa o alcance da comunicação simétrica de dupla via, a qual - mesmo que guardando as devidas proporções quanto às diferentes formas de poder - hoje amplia seu potencial diante das redes sociais online, por exemplo. A internet entra como um meio que descentraliza os modos de publicação das informações e torna organizações e públicos mais próximos (STASIAK, 2013), com usuários produzindo conteúdos (TERRA, 2011).

Nesse sentido, Torquato (2009, p. 16) explica que "pouco se avaliam os níveis de recepção da comunicação". Cabe salientar que, no cenário aqui percebido, há uma dupla análise de recepção: a recepção da comunicação organizacional pelos públicos e, agora, como esses são, também, emissores, inerentemente crossmidiáticos (SCHRØDER, 2011), a recepção e o aproveitamento de suas mensagens pela organização, em uma amostra das possibilidades de simetria de mão dupla, que exige "[...] uma nova filosofia organizacional e a adoção de perspectivas interpretativas [aspectos culturais] e críticas [relações de poder], capazes de incorporarem atitudes coerentes com os anseios da sociedade pós moderna." (KUNSCH, 2009, p. 72). Aí está uma importante faceta da tecnicidade, a intercalação dos papeis de emissor e receptor que retroalimenta o processo de comunicação organizacional - se efetivada a boa prática de dar atenção e fazer a leitura e o feedback ao que o público está comentando.

Os estudos de recepção emergiram ao tomarem posicionamento quanto ao papel ativo e crítico das audiências. Hoje, a demanda é pela atividade dos tradicionais emissores frente às visíveis atuações das tradicionais audiências, para fins de aprendizagem organizacional, gerenciando os inputs e outputs do fluxo comunicacional. Por isso, como posto por Corrêa (2009), há uma adaptação de todas as esferas da comunicação integrada diante da comunicação digital, há uma demanda por um posicionamento estratégico na presença digital, sempre em consonância com os públicos e a cultura organizacional.

Para além de toda inovação que afeta a comunicação interna e externa, entretanto, a base do relacionamento continua a mesma. É preciso seguir os princípios norteadores da comunicação organizacional, primando por boas práticas, aliadas à transparência e à facilidade de comunicação, conferida pelas tecnologias digitais. Nesse 
sentido, é preciso observar as diferentes dimensões da comunicação organizacional, conforme exposto por Baldissera (2009b), na classificação da organização comunicada, comunicante e falada.

A dimensão da organização comunicada (BALDISSERA, 2009b), compreende toda a fala planejada e autorizada da organização, nos âmbitos da sua emissão oficial, enquanto a organização comunicante é a dimensão em que ocorre a interação do público com espaços de fala oficial. Já, a dimensão da organização falada remete ao todo de comunicação que foge ao controle da organização, sendo tudo que se processa em espaços, em que a organização não consegue administrar, a menos que monitore e, a partir disso, reelabore suas estratégias de comunicação na dimensão comunicada.

Conforme Baldissera (2009b), a comunicação como partilha também é disputa de poder - a essência é a mesma, porém, com novos espaços de encontro e novos postos de poder. Pensar essas três dimensões da comunicação organizacional é uma forma de ver os diferentes desafios que emergem aos gestores de comunicação na contemporaneidade. É preciso uma práxis reflexiva das relações públicas, no contexto da sociedade midiatizada, como coloca Lasta (2015), o que envolve a análise das relações com diferentes alteridades no processo de comunicar.. A mediação estrutural da tecnicidade (MARTÍN-BARBERO, 2010), dessa forma, é sentida na realidade organizacional, dentre outros espaços sociais, e traz a necessidade de pesquisas empíricas para expandir e aprofundar as reflexões acerca deste cenário.

\section{Protocolos emergentes na mediação estrutural da tecnicidade}

As reflexões teóricas aqui trazidas colaboram para elucidar este cenário de reconfiguração, do qual as organizações citadas fazem parte. As entrevistas realizadas tiveram um roteiro semiestruturado que foi composto, a fim de investigar o histórico e a estrutura da comunicação; a rotina de trabalho e os processos decisórios diante das redes sociais na web; o processamento e a regulação das informações que circulam em tais redes sobre a organização - o que implica questões de público versus privado, documentos orientadores de ações, monitoramento e sistematização de dados - e, o gerenciamento de crises.

A partir dos dados coletados, pode-se compartilhar que a universidade federal abrange um público de mais de 30 mil pessoas, considerando alunos e servidores e existe a 
mais de 120 anos, considerando desde os seus primeiros cursos de graduação. A concessionária, por sua vez, administra mais de 120 quilômetros de rodovias duplicadas, com mais de 20 anos de atuação no estado do Rio Grande do Sul e faz parte de uma empresa do setor de infraestrutura que administra outros espaços no país. Já a organização hospitalar tem mais de 200 anos de história e consiste em um complexo de sete hospitais, um centro cultural, um cemitério e uma casa de apoio e acolhida para familiares dos pacientes que vêm do interior.

Verificou-se que as três organizações têm perfil nas redes sociais Facebook, Twitter e Instagram, dentre outras redes, sendo essas as principais para o relacionamento com os públicos - cada uma utilizada de uma forma específica por parte dos departamentos de comunicação. Percebeu-se que na universidade, a entrada nas redes sociais foi fruto de planejamento coletivo do setor. 0 maior desafio era como mediar o que chegava. A decisão foi: "comentários que chegam, o setor de comunicação apenas indica quem responde a respeito dentro da universidade", conforme a entrevistada que é jornalista de tal organização. Em 2016, houve uma inovação na interlocução com o público com a criação de uma personagem na página da universidade no Facebook. Era alguém falando em nome da universidade, e o público aderiu à brincadeira e interagiu. Isso surgiu como fruto de sensibilidade, de humanização da 'marca', no principal espaço de comunicação, o qual já extrapolou a assessoria de imprensa e, hoje, é relacionamento com vários públicos.

Um grande desafio, no caso da universidade, por ser pública, é a necessidade de postar conteúdo sem a possibilidade de patrocínio. Além disso, há a questão polêmica de um órgão governamental estar exposto oficialmente em uma rede social que é uma empresa, no caso mais movimentado aqui, o Facebook. Para isso, há um encontro de gestores da comunicação governamental, o evento E-gov, onde profissionais discutem posicionamentos mais adequados para a comunicação de órgãos públicos na internet. Há um planejamento interno para gestão de conteúdos de tudo na web. Não é bom passar de cinco postagens por dia, mas não é um critério rígido - são em torno de cinco. A reação do público é que vai definindo as quantidades e as frequências de postagens. Há um monitoramento todos os dias. Não precisa fazer relatório, mas há discussão em reuniões periódicas. As mídias sociais estão em constante discussão. A política de interação é a mesma em todas as redes sociais.

No caso das outras duas organizações pesquisadas, as decisões também são tomadas coletivamente no setor. Para situações de rotina, já há um protocolo estabelecido. Para situações inusitadas, há uma tomada de decisão a partir de reuniões emergenciais que 
analisam o contexto do fato envolvido na postagem. Em relação ao aproveitamento e à avaliação das informações provenientes dos públicos que circulam na web, tem-se, de modo geral, nas três organizações, certa rotina já estabelecida. No caso da universidade, foi criado um regramento. Não ocultariam as mensagens que chegassem, a menos que fossem de caráter racista, homofóbico, etc. Poucas vezes aconteceu de ter que excluir ou ocultar comentários, em comparação com o volume de comentários que circulam sobre a universidade. De modo geral, há um monitoramento das dúvidas que surgem nos comentários. E, então, os comentários ficam ali, e, depois, um material é elaborado para responder a todos em uma nova publicação. Sempre há discussão coletiva, e opta-se pelo meio termo no posicionamento, visto que o setor não dá conta de responder a todos.

Já na concessionária, as notícias de impacto no trânsito e as dúvidas rotineiras têm respostas pré-estabelecidas. Quando é pergunta que necessita de uma explicação maior, a assessoria encaminha para a ouvidoria, já que os 140 caracteres do Twitter não são suficientes para esta interação. O Facebook, por sua vez, é mais usado para campanhas de educação para o trânsito e para comunicação institucional. A interação se dá mais a partir de postagens da organização e de dúvidas levantadas pelo público. Depoimento das pessoas, por exemplo, são muito utilizados no Facebook. São campanhas educacionais constantes, algumas com publicações impulsionadas por patrocínio na própria rede social. De modo geral, há uma cultura de não investir em mídia paga, exceto na divulgação do balanço social. A verba para impulsionar as postagens no Facebook é pequena, mas sem isso o alcance é muito baixo. A audiência aumenta em situações de crise, como acidentes, e no verão (200 mil acessos em alguns momentos de saída para a praia, e 40 mil pessoas conectadas ao mesmo tempo no aplicativo criado pelo setor - no qual convergem a rádio e as câmeras da rodovia), por exemplo. Há, também, um aplicativo para entreter as crianças no trânsito.

0 padrão de interação no Facebook é responder mensagem rapidamente, mas há dúvidas quanto ao posicionamento para além disso. Críticas e perguntas são, geralmente, respondidas nos comentários, porém, ficar curtindo os comentários não é uma prática, visto que há dúvidas como "quando é crítica, deve curtir?", conforme uma das jornalistas entrevistadas. Não houve necessidade de deletar comentários, mas houve dois episódios de princípio de crise que foram solucionados com o apoio do uso dos perfis pessoais das gestoras de comunicação. O monitoramento em caso de crise é mais manual, e, até o momento, não houve necessidade de terceirizá-lo. Há tentativa de mensuração de elogios, críticas, sugestões, e outros comentários positivos e negativos. 
Há um projeto de monitoramento interno que cruza o fluxo da rodovia com o fluxo das redes sociais, no chamado Dashboard (painel), que mostra quantos carros estão na rodovia, quantos usuários estão conectados, quantos estão marcando o perfil da organização em suas postagens, quantos estão curtindo, quantos ligam para o atendimento, etc. É o uso de big data, com a visualização de nuvens de informações, oscilações nos fluxos e monitoramento de palavra-chave. 0 painel permite uma visão sistêmica e simultânea dos dados. É ferramenta personalizada para esse tipo de negócio que acaba permitindo uma memória da comunicação organizacional que ocorre nas redes sociais. A partir dos dados, é possível ter insights importantes para estratégias de comunicação. 0 usuário acessa ao site antes de sair de casa para a praia e, na volta, acessa mais o aplicativo no celular - conforme os dados de tráfego na internet.

$\mathrm{Na}$ organização hospitalar, há o planejamento editorial para as postagens, com pautas momentâneas que se encaixam nas datas comemorativas e nos eventos institucionais. Há um planejamento anual com ações para mulheres, homens, idosos, aniversário de hospitais e divulgação de eventos internos. A ideia não é vincular vendas no Facebook, visto que o foco nessa rede social é na comunicação institucional. Prevenção e educação para a saúde, assim como da concessionária que trabalha na educação para o trânsito. Raramente há postagens patrocinadas, no caso da organização hospitalar.

0 gestor entrevistado é quem faz o planejamento e posta nas mídias sociais, e todas as manhãs lê os comentários que chegam, mas nem sempre dá conta do grande volume. Não curte os comentários porque "fica chato esquecer de curtir algum", conforme dito em entrevista. Quando são perguntas, eles respondem. Dependendo da crítica, é feito o encaminhado à ouvidoria, visto que há um fluxo para o gerenciamento de crise neste setor. Além disso, há o aplicativo na página do Facebook que remete à Ouvidoria, e também, tem um aplicativo para agendamento de consultas. Ambos surgiram por demanda, no Facebook e no site. Será ainda feito um aplicativo para doações e tudo isso é negociado com o fornecedor do site.

Na universidade e na organização hospitalar, o grande desafio é a gestão das páginas alternativas que parecem oficiais, mas não são, uma vez que não passam pelo crivo profissional da assessoria de comunicação. Não há padronização nas unidades que compõe a organização. Não há um preparo para isso. Há apenas menção às regras de uso na apresentação da assessoria da universidade na página do Facebook. Já a concessionária de rodovias ministra curso de redes sociais para os seus funcionários, como um treinamento, 
para que esses não só não exponham aquilo que é informação de dentro da empresa, mas também não deixem de ter a liberdade de postar conteúdos que mostrem o seu orgulho ao chegar ao trabalho e compartilhar com sua rede social a sua alegria ao citar a empresa. É um media training interno. É preciso muito cuidado com fotos e filmagens de acidentes na rodovia, por exemplo, às quais os funcionários têm acesso e podem, ingenuamente, compartilhar. É preciso zelar pela preservação da imagem das pessoas. Há a questão de engajamento e do risco potencial que um funcionário representa nas redes sociais. Há dimensões técnicas, pessoais e institucionais a serem consideradas. Olhar o por do sol além da rodovia, por exemplo, é um bom exemplo de postagem de funcionário que compartilha foto da janela de sua sala de trabalho. Há diferentes instâncias de relacionamento e exposição.

Além deste treinamento, no manual de integração do holding da qual a concessionária faz parte, há citação de questões referentes às redes sociais. É um código de conduta da empresa que orienta para o cuidado com a divulgação de informações. Além disso, em função dos desafios envolvendo postagens inadequadas de funcionários em relação ao serviço na organização hospitalar, foi criado um documento de boas práticas nas redes sociais, de circulação interna. Fotos de bloco cirúrgico e de funcionários tomando chimarrão no plantão eram conteúdos frequentes nas postagens dos funcionários - o que alertou para a necessidade de um posicionamento oficial por parte do departamento de comunicação.

Desse modo, os dados coletados nas entrevistas, mostraram como tem se dado a gestão das diferentes possibilidades de comunicação organizacional a partir das tecnologias de informação e comunicação, em organizações que são, aqui, um exemplo de primeiro, segundo e terceiro setor. Com isso, é possível compreender o atual patamar de mediação da tecnicidade. Percebe-se que esta gestão tem se estruturado por meio da definição ou da tentativa diária de estabelecimentos de protocolos de emissão, regulação, interação, recepção/monitoramento, registro e análise, gerenciamento de crise e inovação, a partir de demandas, conforme resumido, comparativamente, entre as organizações pesquisadas, no quadro a seguir. 
Quadro 1 - Protocolos de comunicação organizacional no patamar de mediação estrutural da tecnicidade

\begin{tabular}{|c|c|c|c|}
\hline $\begin{array}{c}\text { PROTOCOLOS DA MEDIAÇÃO } \\
\text { ESTRUTURAL DA } \\
\text { TECNICIDADE }\end{array}$ & $\begin{array}{l}\text { Universidade } \\
\text { Federal }\end{array}$ & $\begin{array}{l}\text { Concessionária de } \\
\text { Rodovias }\end{array}$ & $\begin{array}{l}\text { Organização } \\
\text { Hospitalar }\end{array}$ \\
\hline $\begin{array}{l}\text { PROTOCOLO DE EMISSÃO } \\
\text { (Posicionamento editorial) }\end{array}$ & $\begin{array}{l}\text { Com planejamento } \\
\text { focado em } \\
\text { assessoria de } \\
\text { imprensa. Página } \\
\text { reconhecida como } \\
\text { fonte oficial pela } \\
\text { imprensa local. }\end{array}$ & $\begin{array}{l}\text { Cada mídia social tem } \\
\text { sua peculiaridade. } \\
\text { Twitter tem notícia } \\
\text { sobre trânsito e } \\
\text { Facebook tem } \\
\text { campanhas educativas } \\
\text { para o trânsito. }\end{array}$ & $\begin{array}{c}\text { Foco no } \\
\text { Facebook, } \\
\text { campanhas } \\
\text { educativas de } \\
\text { saúde e } \\
\text { relacionamento. }\end{array}$ \\
\hline $\begin{array}{l}\text { PROTOCOLO DE REGULAÇÃO } \\
\text { INTERNA E EXTERNA } \\
\text { (Documentos orientadores } \\
\text { para o público interno e } \\
\text { regras de uso explícitas nas } \\
\text { mídias sociais) }\end{array}$ & $\begin{array}{l}\text { Não tem protocolos } \\
\text { elaborados. Há } \\
\text { apenas uma frase } \\
\text { que menciona que } \\
\text { comentários } \\
\text { ofensivos serão } \\
\text { excluídos do } \\
\text { Facebook. }\end{array}$ & $\begin{array}{l}\text { Tem capacitação para } \\
\text { público interno e } \\
\text { menção sobre uso de } \\
\text { redes sociais no } \\
\text { documento de código } \\
\text { de conduta. }\end{array}$ & $\begin{array}{c}\text { Tem regras de } \\
\text { uso explícitas } \\
\text { na página do } \\
\text { Facebook e tem } \\
\text { documento } \\
\text { especial para } \\
\text { público interno, } \\
\text { sobre boas } \\
\text { práticas. }\end{array}$ \\
\hline $\begin{array}{l}\text { PROTOCOLO DE INTERAÇÃO } \\
\text { (Política de interação) }\end{array}$ & $\begin{array}{l}\text { Em processo, nem } \\
\text { tudo é respondido. }\end{array}$ & $\begin{array}{l}\text { Em processo, nem } \\
\text { tudo é respondido } \\
\text { (exceto no Twitter). }\end{array}$ & $\begin{array}{l}\text { Em processo, } \\
\text { nem tudo é } \\
\text { respondido. }\end{array}$ \\
\hline $\begin{array}{c}\text { PROTOCOLO DE } \\
\text { RECEPÇÃO/MONITORAMENTO } \\
\text { (Observação e controle de } \\
\text { informações sobre a } \\
\text { organização) }\end{array}$ & $\begin{array}{c}\text { Empresa } \\
\text { terceirizada } \\
\text { fornece material } \\
\text { bruto com menções } \\
\text { à universidade na } \\
\text { internet. } \\
\end{array}$ & $\begin{array}{c}\text { Deshboard, } \\
\text { convergência de } \\
\text { dados de fluxo de } \\
\text { trânsito e de menções } \\
\text { à empresa na internet. }\end{array}$ & $\begin{array}{l}\text { Parcial e } \\
\text { manual, sempre } \\
\text { que possível. }\end{array}$ \\
\hline $\begin{array}{c}\text { PROTOCOLO DE REGISTRO E } \\
\text { ANÁLISE (Sistematização e } \\
\text { relatórios) }\end{array}$ & $\begin{array}{l}\text { Há apenas material } \\
\text { bruto fornecido } \\
\text { pela empresa } \\
\text { terceirizada. }\end{array}$ & $\begin{array}{l}\text { Há informações } \\
\text { quantitativas } \\
\text { provenientes do } \\
\text { deshboard. }\end{array}$ & Não há. \\
\hline $\begin{array}{c}\text { PROTOCOLO DE } \\
\text { GERENCIAMENTO DE CRISE } \\
\text { (Gerenciamento de crises) }\end{array}$ & $\begin{array}{l}\text { Crises pontuais são } \\
\text { gerenciadas de } \\
\text { modo contextual, } \\
\text { não há protocolo } \\
\text { determinado de } \\
\text { prevenção ou } \\
\text { gerenciamento de } \\
\text { crise. }\end{array}$ & $\begin{array}{l}\text { Crises pontuais são } \\
\text { gerenciadas de modo } \\
\text { contextual, não há } \\
\text { protocolo } \\
\text { determinado de } \\
\text { prevenção ou } \\
\text { gerenciamento de } \\
\text { crise. }\end{array}$ & $\begin{array}{l}\text { Crises pontuais } \\
\text { são gerenciadas } \\
\text { de modo } \\
\text { contextual, não } \\
\text { há protocolo } \\
\text { determinado de } \\
\text { prevenção ou } \\
\text { gerenciamento } \\
\text { de crise. }\end{array}$ \\
\hline $\begin{array}{l}\text { PROTOCOLO DE INOVAÇÃO E } \\
\text { GESTÃO DE DEMANDAS } \\
\text { (Produtos diferenciados) }\end{array}$ & Não há. & $\begin{array}{c}\text { Aplicativo de } \\
\text { mobilidade que faz } \\
\text { convergir Twitter, } \\
\text { rádio e câmeras. } \\
\text { Aplicativos para } \\
\text { crianças. Contratação } \\
\text { de deshboard. }\end{array}$ & $\begin{array}{l}\text { Aplicativos no } \\
\text { próprio } \\
\text { Facebook para } \\
\text { agendamento } \\
\text { de consultas e } \\
\text { ouvidoria. }\end{array}$ \\
\hline
\end{tabular}

Fonte: Elaborado pela autora. 
Fazer a gestão do que Baldissera (2009a) entende como organização comunicada, que é a ação planejada, em que a organização detém o controle informacional, demanda protocolos de emissão, planejamento de conteúdos e de frequência de postagens. Já a esfera da organização comunicante, conforme o autor, podemos perceber contemplada nos protocolos de interação e regulação interna e externa das formas de interação, via regras de interação nas páginas do Facebook, por exemplo, ou documentos orientadores oficiais da conduta dos funcionários. A organização falada, por sua vez, esfera onde a organização não tem controle, pode ser alcançada via protocolos de recepção/monitoramento, para analisar comentários e reelaborar estratégias de comunicação e interação. 0 registro e a análise de dados, assim como os protocolos de inovação a partir de demandas, decorrem da análise de todas essas esferas da comunicação organizacional.

Ao identificar estes protocolos diversos como a resposta ao problema de pesquisa, alcança-se o objetivo e evidencia-se que o processo de reconfiguração da comunicação organizacional, no atual patamar de mediação da tecnicidade (MARTÍN-BARBERO, 2010) e na relação com os diferentes públicos nas redes sociais da web é um desafio diário e permanente nas três organizações investigadas, de fluxo contínuo, que depende de análise e discussão constantes. Junto da surpresa em relação à reação dos públicos diante de cada postagem, há o desafio da interface técnica, como os algoritmos das redes sociais que condicionam e pré-determinam o alcance de visualização dos conteúdos. São muitas as variáveis que interferem nesse processo, o que exige postura alerta dos gestores de comunicação e busca constante do exercício do modelo simétrico de duas mãos (GRUNIG, 2011).

Além disso, as diferentes camadas identitárias e relacionais misturam-se, com os perfis pessoais e as ocupações profissionais dos funcionários das organizações. Isso tanto na instância dos gestores da comunicação com seus perfis pessoais, tendo que dar conta de falar em nome da empresa em muitas situações, quanto no controle do que os funcionários, de modo geral, postam a respeito da empresa. Ou seja, a mediação estrutural da tecnicidade (MARTÍN-BARBERO, 2010) permeia todas as instâncias comunicacionais das organizaçoes.

Sem falar no caráter privado que tem as redes socias que as organizações utilizam para criar seus canais oficias de comunicação de modo gratuito. Este é um outro grande problema a ser enfrentado, principalmente, por uma instituição pública, como o caso da 
universidade pesquisada, que deposita suas informações de assessoria de imprensa em um site que tem um proprietário, como o Facebook. Ao mesmo tempo que é importante estar nas redes sociais da internet, para ampliar o contato com os públicos, é preciso ter cuidado com a segurança das informações e do registro de uma memória da comunicação organizacional ali depositada. Percebe-se, de modo geral, que o organização privada, a concessionária de rodovias, tem suas estratégias mais bem elaboradas, mas, mesmo assim, enfrenta os desafios que as organizações do primeiro e do terceiro setor aqui representadas também enfrentam.

\section{Considerações}

As reflexões que partem do empírico evidenciam desafios semelhantes enfrentados pelos gestores da comunicação nas diferentes organizações. Entre os dados que mais se destacam está a gestão do grande volume de dados e o protocolo de interação frente as diferentes demandas. Além disso, percebe-se que este cenário demanda constante atualização dos profissionais e permanente controle do fluxo de informações que circulam nas mídias sociais. Dentre os três exemplos contemplados nessa pesquisa, tem-se, no segundo setor, uma diversidade maior de estratégias envolvendo a comunicação digital, o que é natural, tendo em vista a autonomia na gestão dos recursos financeiros.

Junto disso, compreende-se que as transformações nas estratégias de gestão da comunicação sempre estiveram acompanhadas das inovações nos meios de comunicação, porém, a partir da web, as possibilidades de emissão se expandiram e aí se encontra o grande desafio. Pensando nas possibilidades técnicas, públicos e organizações detêm os mesmos privilégios de atuação nos espaços digitais. E os diferentes sujeitos envolvidos nesta relação de comunicação têm suas esferas de vida pública e privada em conflito, o que tem se tornado um grande desafio na contemporaneidade.

O conceito de mediação estrutural da tecnicidade, de Jesús Martin-Barbero (2010), portanto, colabora para elucidar estes processos de reconfiguração da comunicação organizacional na contemporaneidade e mostra-se, empiricamente, a partir da demanda por protocolos diversos. Conforme os resultados explicitados, tais protocolos são a materialização dos desafios emergentes no trânsito das audiências, onde organizações e públicos intercalam papeis de emissão e recepção no processo de interação em torno da comunicação organizacional. E em meio a isso tudo, é preciso ter como foco a comunicação 
excelente, na qual haja de fato a partilha de sentidos e o respeito humano na comunicação e no atendimento das demandas sociais, com postura ética, crítica e socialmente responsável.

\section{Referências}

BALDISSERA, Rudimar. A teoria da complexidade e novas perspectivas para os estudos de comunicação organizacional. In: KUNSCH, Margarida Maria Krohling. Comunicação organizacional: histórico, fundamentos e processos. São Paulo: Saraiva, 2009a.

BALDISSERA, Rudimar. Comunicação organizacional na perspectiva da complexidade. Organicom, São Paulo, v. 6, n. 10, 2009b.

CORRÊA, Elizabeth Saad. Comunicação digital e novas mídias institucionais. In: KUNSCH, Margarida Maria Krohling. Comunicação organizacional: histórico, fundamentos e processos. São Paulo: Saraiva, 2009.

FAUSTO NETO, Antonio. Fragmentos de uma analítica da midiatização. Matrizes, São Paulo, v. 1 , n. 2, p. 89-105, abr. 2008.

GRUNIG, James. Definição e posicionamento das Relações Públicas. In: GRUNIG, James E.; FRANÇA, Fábio; FERRARI, Maria Cristina (Org.). Relações Públicas: teoria, contexto e relacionamentos. São Caetano do Sul: Difusão Editora, 2011.

JENKINS, Henry. Cultura da convergência. São Paulo: Aleph, 2008.

KEGLER, Jaqueline Quincozes da Silva. Comunicação pública e complexidade: uma perspectiva das relações Públicas como sujeito comunicacional e estratégico no cenário da midiatização. 2008. Dissertação (Mestrado em Comunicação) - Programa de Pós-Graduação em Comunicação, Universidade Federal de Santa Maria, Santa Maria, 2008.

KUNSCH, Margarida Maria Krohling. Planejamento de relações públicas na comunicação integrada. São Paulo: Summus, 2003.

KUNSCH, Margarida Maria Krohling. Percursos paradigmáticos e avanços epistemológicos nos estudos de comunicação organizacional. In: KUNSCH, Margarida Maria Krohling. Comunicação organizacional: histórico, fundamentos e processos. São Paulo: Saraiva, 2009.

LASTA, Elisângela. A práxis reflexiva das relações públicas na sociedade midiatizada: mediação estratégica comunicacional nos blogs corporativos. 2015. Tese (Doutorado em Comunicação), Programa de Pós-Graduação em Comunicação, Universidade Federal de Santa Maria, Santa Maria, 2015.

MARTÍN-BARBERO, Jesús. Razon técnica y razon política: espacios/tiempos no pensados. Revista Alaic, São Paulo, n. 1, 2004. 
MARTÍN-BARBERO, Jesús. Dos meios às mediações: comunicação, cultura e hegemonia. 5 . ed. Rio de Janeiro: UFRJ, 2008.

MARTÍN-BARBERO, Jesús. Uma aventura epistemológica [entrevista]. Entrevistadora: Maria Immacolata Vassalo de Lopes. Matrizes, São Paulo, v. 2, n. 2, 2009.

MARTÍN-BARBERO, Jesús. Convergencia digital y diversidade cultural. In: MORAES, Dênis de. Mutaciones de lo visible: communicación y processos culturales em la era digital. Buenos Aires: Paidós, 2010.

OROZCO-GÓMEZ, Guillermo. La condición comunicacional contemporânea. Desafios latinoamericanos de la investigación de las interaciones em la sociedade red. In: JACKS, Nilda (Org.). Analisis de recepción en América Latina: um recuento histórico com perspectivas al futuro. Quito: Centro Internacional de Estudios Superiores de Comunicación para América Latina en Quito, 2011.

PIENIZ, Mônica. Tecnicidade como mediação empírica: a reconfiguração da recepção de telenovela a partir do Twitter. 2013. Tese (Doutorado em Comunicação e Informação)Programa de Pós-Graduação em Comunicação e Informação, Universidade Federal do Rio Grande do Sul, Porto Alegre, 2013.

PIENIZ, Mônica. Mediação estrutural da tecnicidade: o trânsito das audiências a partir do Twitter. Matrizes, São Paulo, v.9, n. 1, 2015a, p. 213-228.

PIENIZ, Mônica. Tecnicidade como mediação estrutural no processo de trânsito das audiências: apontamentos para a comunicação organizacional contemporânea". Organicom, São Paulo, v. 12, n. 22, p. 57-66, 2015b.

PRIMO, Alex. Interação mediada por computador. Porto Alegre: Sulina, 2008.

SCHRØDER, Kim Christian. Audiences are inherently cross-media: audience studies and the cross-media challenge. Communication and Media, Belgrade, v. 6, n. 18, p. 5-28, 2011.

STASIAK, Daiana. A comunicação organizacional sob o viés da midiatização: outros fluxos, novas percepções. In: NOVELLI, Ana Lúcia; MOURA, Cláudia Peixoto de; CURVELLO, João José Azevedo. ABRAPCORP 2013: teorias e métodos de pesquisa em comunicação organizacional e relações públicas: entre a tradição e a inovação. Porto Alegre: Edipucrs, 2013.

TERRA, Carolina Frazon. Mídias sociais... e agora?: o que você precisa saber para implementar um projeto de mídias sociais. São Caetano do Sul: Difusão Editora, 2011.

TORQUATO, Gaudêncio. Da gênese do jornalismo empresarial e das relações públicas à comunicação organizacional no Brasil. In: KUNSCH, Margarida Maria Krohling.

Comunicação organizacional: histórico, fundamentos e processos. São Paulo: Saraiva, 2009. 


\title{
Emerging protocols in the organizational communication at the current level of structural mediation of technicality
}

\begin{abstract}
This article presents the results of a research whose general objective was to understand the process of reconfiguration of organizational communication in the current level of mediation of technicality in relation to the different publics. This research seeks to answer the following question: how is the management of the different possibilities of organizational communication from information and communication technologies in organizations representing the first, second and third sectors? Interviews with managers of organizational communication were the technique used for collecting data. The results point to the constitution of different types of protocols in the management of communication in organizations, such as issuance, interaction, reception/monitoring, regulation, crisis management, registration and analysis and innovation on demand.
\end{abstract}

\section{Keywords}

Structural mediation of technicality. Media convergence. Organizational communication. Communication management. Reception.

Recebido em 14/03/2018

Aceito em 08/05/2018 